\title{
Clinical and inflammatory determinants of bronchial hyperresponsiveness in COPD
}

\author{
Maarten van den Berge*,\#, Judith M. Vonk ${ }^{\#, \oplus, ~ M a r g o t ~ G o s m a n ~}{ }^{+}$, Thérèse \\ S. Lapperre ${ }^{\S}$, Jiska B. Snoeck-Stroband ${ }^{f}$, Peter J. Sterk**, Lisette I.Z. Kunz ${ }^{\S}$, \\ Pieter S. Hiemstra ${ }^{\S}$, Wim Timens ${ }^{\# \# \#}$, Nick H.T. ten Hacken*,\#, \\ Huib A.M. Kerstjens*,\# and Dirkje S. Postma*,\#
}

ABSTRACT: Bronchial hyperresponsiveness (BHR) is regarded as a hallmark of asthma, yet it is also present in a considerable number of chronic obstructive pulmonary disease (COPD) patients. Epidemiological studies have shown that BHR provides complementary information to forced expiratory volume in $1 \mathrm{~s}$ (FEV 1 ) for development and progression of COPD. We hypothesised that the severity of BHR and its longitudinal changes associate with both clinical and airway inflammation measures in COPD.

Our hypothesis was tested in 114 COPD patients (median age 62.9 years, smoking exposure 45.9 pack-yrs) participating in the GLUCOLD (Groningen Leiden Universities Corticosteroids in Obstructive Lung Disease) study, which previously showed an improvement in BHR with fluticasone and fluticasone/salmeterol. At baseline, and 6 and 30 months after treatment, we investigated lung function, including body plethysmography, provocative concentration of methacholine causing a $20 \%$ fall in FEV 1 , sputum induction, and bronchial biopsies.

By performing both cross-sectional and longitudinal analyses, we show that BHR in COPD is predominantly associated with residual volume/total lung capacity (a measure of air trapping) and airway inflammation reflected by the number of neutrophils, macrophages and lymphocytes in sputum and bronchial biopsies.

Our findings indicate that BHR is an independent trait in COPD and provides important information on phenotype heterogeneity and disease activity.

KEYWORDS: Bronchial biopsies, bronchial hyperresponsiveness, chronic obstructive pulmonary disease, methacholine, neutrophils, sputum

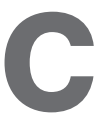
hronic obstructive pulmonary disease (COPD) has a major health impact throughout the world $[1,2]$. Patients with COPD generally show a progressive lung function loss with a concomitant reduction in health status and increase in symptoms. Some of these symptoms, such as a sudden increase in cough and dyspnoea when inhaling cold, air are due to bronchial hyperresponsiveness (BHR). BHR is often thought to be a hallmark of asthma, yet it has been shown to occur in up to two-thirds of patients with COPD as well [3]. In asthma, BHR is associated with both baseline level of forced expiratory volume in $1 \mathrm{~s}$ (FEV1) and eosinophilic airway inflammation measured in peripheral blood, sputum, bronchoalveolar lavage or bronchial biopsies $[4,5]$. Thus far, the factors underlying BHR in COPD remain largely unknown. Since patients with COPD invariably have airway obstruction that is often quite severe, it has been argued that the presence of $\mathrm{BHR}$ in COPD merely reflects a lower prechallenge FEV1 and is not of pathophysiological importance [6, 7]. An argument against this assumption is the observation that the presence of BHR precedes the development of COPD-like symptoms in the general population [8]. In addition, a more severe BHR is associated with an accelerated decline in lung function in COPD patients even after adjusting for baseline FEV1 $[9,10]$. Furthermore, the severity of BHR is an independent predictor of improvement in FEV1 after smoking cessation in patients with mild-tomoderate COPD participating in the Lung Health Study [11]. Given these observations, it is important to further explore the underlying physiology of BHR in COPD.

For editorial comments see page 1067.

This article has supplementary material available from www.erj.ersjournals.com

AFFILIATIONS

*Dept of Pulmonary Diseases,

University Medical Center Groningen University of Groningen,

'Dept of Epidemiology, University

Medical Center Groningen, University of Groningen,

\#\#Dept of Pathology, University Medical Center Groningen, University of Groningen,

\#Groningen Research Institute for Asthma and COPD, Groningen, +Dept of Neurology, University Hospital Nijmegen, Nijmegen, ${ }^{\S}$ Dept of Pulmonology, University Medical Center,

${ }^{f}$ Dept of Medical Decision Making, University Medical Center, Leiden, and

**Dept of Respiratory Medicine, Academic Medical Centre, University of Amsterdam, Amsterdam, The Netherlands

CORRESPONDENCE

M. van den Berge Dept of Pulmonary Diseases, University Medical Center Groningen University of Groningen Hanzeplein 1 9713 GZ

Groningen

The Netherlands

E-mail: m.van.den.berge@ long.umcg.nl

Received:

Sept 302011

Accepted after revision: Jan 252012

First published online: April 202012 
The GLUCOLD (Groningen Leiden Universities Corticosteroids in Obstructive Lung Disease) study showed an improvement in FEV1 and BHR after treatment with fluticasone or fluticasone/salmeterol for up to 30 months, and, at the same time, improvements in inflammatory parameters in patients with mild-to-moderate COPD [12]. We hypothesised that the severity of BHR and its longitudinal changes are not only associated with lung function, but also with the extent of airway inflammation in patients with COPD. The GLUCOLD study provides an excellent opportunity to investigate this, since all patients were extensively characterised before, and 6 and 30 months after treatment with inhaled corticosteroids (ICSs) with or without a long-acting $\beta$-agonist, or placebo.

\section{METHODS}

\section{Patients}

114 with COPD participating in the GLUCOLD study were included [12]. The GLUCOLD study enrolled patients with COPD in Global Initiative for Chronic Obstructive Lung Disease stages II and III who were aged 40-75 yrs and current or former smokers with $\geqslant 10$ pack-yrs smoking exposure. Exclusion criteria were a history of asthma and the use of ICSs and oral corticosteroids within 6 months prior to the start of the study.

\section{Study design}

The study design of the GLUCOLD study has been described in detail previously [12]. In brief, patients were randomly assigned to receive one out of four double-blind treatments: 1) fluticasone $(500 \mu \mathrm{g})$ b.i.d. for 30 months; 2) fluticasone/salmeterol $(500 / 50 \mu \mathrm{g})$ b.i.d. for 30 months; 3) fluticasone $(500 \mu \mathrm{g})$ b.i.d. for the first 6 months followed by placebo b.i.d. for 24 months; or 4) placebo b.i.d. for 30 months (fig. 1). At baseline, and after 6 and 30 months of treatment, the following investigations were performed: spirometry; body plethysmography; provocative concentration of methacholine causing a fall in FEV1 of 20\% (PC20); blood collection; sputum induction; and bronchoscopy with bronchial biopsies. The study was carried out in two Dutch centres (University Medical Center Groningen and the Leiden University Medical Center). Both centres' ethics committees approved the study and all patients provided written informed consent.

\section{Lung function and $B H R$}

FEV1 was measured with a daily-calibrated pneumotachograph (Masterscreen Pneumo; Jaeger, Wurzburg, Germany) according to standardised guidelines. Methacholine PC20 was measured by the 2-min tidal breathing method as described previously [13]. Patients were considered to be hyperresponsive when they had a methacholine bromide PC20 $\leqslant 9.6 \mathrm{mg} \cdot \mathrm{mL}^{-1}$, corresponding to a methacholine chloride PC20 $<8 \mathrm{mg} \cdot \mathrm{mL}^{-1}$ on a molar basis [13]. Total lung capacity (TLC), residual volume (RV) and inspiratory capacity were measured using a constant volume body plethysmograph according to standardised guidelines [14].

\section{Sputum induction and sputum processing}

Sputum was induced by inhalation of hypertonic saline aerosols as previously described [15]. $15 \mathrm{~min}$ after salbutamol $(200 \mu \mathrm{g})$ inhalation, $4.5 \%$ hypertonic saline was nebulised three times over $5 \mathrm{~min}$. Whole samples were processed according to the method described by FAHY et al. [16].

\section{Bronchoscopic biopsy analyses}

The methods for biopsy processing, staining and analysis have been described in detail previously [17]. In short, 4- $\mu \mathrm{m}$ thick,

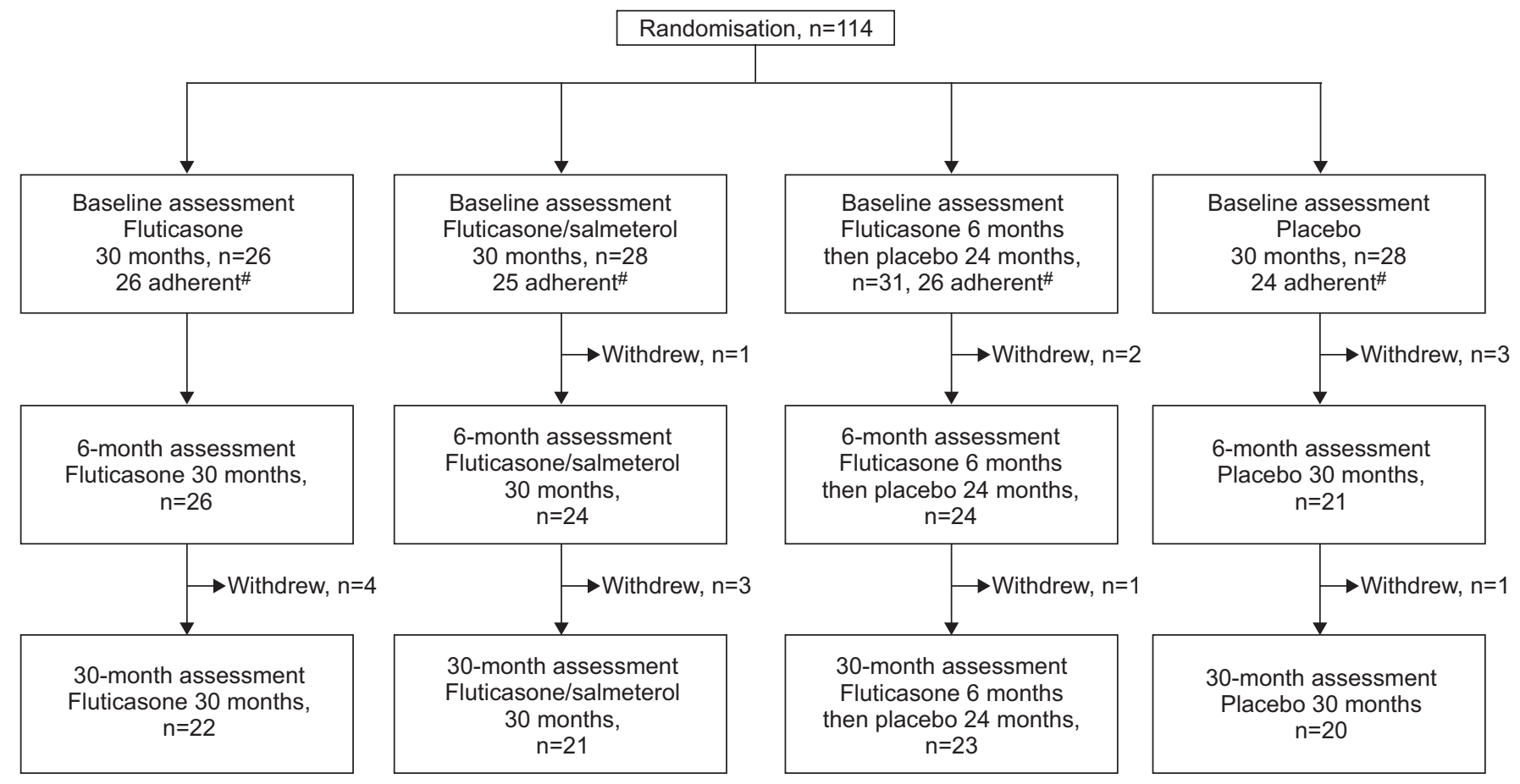

FIGURE 1. Total number of randomised patients who adhered to therapy per treatment group. ${ }^{*}:>70 \%$ medication use. Reproduced and modified from [12] with permission from the publisher. 
paraffin-embedded sections were stained using specific antibodies against T-lymphocytes (anti-CD4 and anti-CD8), macrophages (anti-CD68), neutrophil elastase, mast cell tryptase (AA1), eosinophils (EG2) and plasma cells (anti-CD138). Digital images per coded biopsy section were prepared using a colour camera (A101fc-le; Basler AG, Ahrensburg, Germany) and a dedicated software program (RVC Software, Amersfoort, The Netherlands). These images were united into one large image consisting of the entire biopsy section (100 mm, 115.7 pixels). Numbers of subepithelial, positively staining inflammatory cells were counted within the largest possible area, $\leqslant 125 \mu$ m beneath the basement membrane, per biopsy section, and expressed as the mean number of cells per $0.1 \mathrm{~mm}^{2}$ of two tissue samples per patient.

\section{Statistical analysis}

Mean \pm SD or median (interquartile range) of variables were calculated. When appropriate, variables were normalised by logarithmic transformation before statistical analysis. PC20 calculations were performed using the base-2 logarithm $\left(\log _{2}\right)$, as this reflects doubling concentrations and normalises the distribution [18]. We performed analyses on PC20 at baseline, and on the changes in PC20 during the first 6 months of treatment, and between 6 and 30 months of treatment. Univariate analyses were performed in all patients from all treatment groups. Subsequently, multivariate linear regression analysis was performed in the full cohort with baseline or change in methacholine PC20 as the dependent variable, and age, sex, treatment group and smoking status (current or ex-smoker) as covariates. In addition, we included those variables with the most significant univariate regression coefficients in each of the following categories: 1) lung function; 2) blood cell differential count; 3) sputum cell differential count; and 4) inflammatory cells in bronchial biopsies.

\section{RESULTS}

\section{Participants}

A total of 114 patients with COPD were included in the study. Methacholine PC20 was not determined in four patients because their baseline FEV1 was $<1.2 \mathrm{~L}$. The baseline characteristics of the remaining 110 patients are presented in table 1 . The sputum sample was discarded in eight patients, as it contained $>80 \%$ squamous cells. A bronchoscopy was performed in all patients; one patient had no adequate sample. Blood was collected in all patients. A complete dataset was available for 74 of the 114 patients at baseline. After treatment, 19 patients were withdrawn from further analyses because they did not meet the predefined criteria for treatment compliance or withdrew their consent $(n=6)$. Of the remaining 95 patients, a sputum sample of sufficient quality was obtained in 87 and 80 patients after 6 and 30 months of treatment, and a bronchoscopy was performed in 90 and 77 patients, respectively.

\section{Cross-sectional analysis of methacholine $P_{20}$ at baseline}

From the 110 patients with a methacholine PC20 available at baseline, a total of 103 (94\%) were hyperresponsive. Patients with BHR were more often female, had a higher RV/TLC \% predicted, a higher number of sputum eosinophils and tended to have a lower FEV1/inspiratory vital capacity (IVC) ratio than patients without BHR.

\begin{tabular}{|c|c|c|}
\hline TABLE 1 & \multicolumn{2}{|c|}{$\begin{array}{l}\text { Baseline characteristics and cell count data of } \\
\text { the study population }\end{array}$} \\
\hline \multicolumn{2}{|l|}{ Age yrs } & $62.9(57.0-68.0)$ \\
\hline \multicolumn{2}{|c|}{ Males/females n } & $96 / 14$ \\
\hline \multicolumn{2}{|c|}{ Current smokers \% } & 63 \\
\hline \multicolumn{2}{|c|}{ Smoking exposure pack-yrs } & $41.8(31.2-54.8)$ \\
\hline \multicolumn{2}{|c|}{ Body mass index $\mathrm{kg} \cdot \mathrm{m}^{-2}$} & $25.3(22.4-27.8)$ \\
\hline \multicolumn{2}{|c|}{$\begin{array}{l}\text { Methacholine } \mathrm{PC}_{20} \mathrm{mg} \cdot \mathrm{mL}^{-1} \\
\text { geometric mean (interquartile range) }\end{array}$} & $1.8(0.2-2.4)$ \\
\hline \multicolumn{2}{|c|}{$\mathrm{FEV}_{1}^{\#} \%$ pred } & $64.2(57.1-69.3)$ \\
\hline \multicolumn{2}{|c|}{ FVC $^{\#} \%$ pred } & $99.0(91.3-109.9)$ \\
\hline \multicolumn{2}{|c|}{$\mathrm{FEV}_{1} / \mathrm{IVC}^{\#} \%$} & $45.2(39.3-52.7)$ \\
\hline \multicolumn{2}{|c|}{ RV/TLC $\#$ \% pred } & $125.6(112.6-140.3)$ \\
\hline \multicolumn{2}{|c|}{ IC \% pred } & $72.1(62.7-83.9)$ \\
\hline \multicolumn{2}{|c|}{$T L, C O / V A \%$ pred } & $74.4(57.7-90.0)$ \\
\hline \multicolumn{3}{|c|}{ Blood \% leukocytes } \\
\hline \multicolumn{2}{|c|}{ Neutrophils } & $59.2(52.3-66.3)$ \\
\hline \multicolumn{2}{|l|}{ Eosinophils } & $2.2(1.1-3.3)$ \\
\hline \multicolumn{2}{|l|}{ Monocytes } & $8.7(7.4-10.1)$ \\
\hline \multicolumn{2}{|l|}{ Basophils } & $0.5(0.3-0.8)$ \\
\hline \multicolumn{2}{|c|}{ Lymphocytes } & $28.2(22.3-34.4)$ \\
\hline \multicolumn{3}{|c|}{ Sputum $\times 10^{4}$ cells $\cdot \mathrm{mL}^{-1 \pi}$} \\
\hline \multicolumn{2}{|c|}{ Total cells } & $2.4(2.1-2.6)$ \\
\hline \multicolumn{2}{|c|}{ Macrophages } & $1.5(1.3-1.8)$ \\
\hline \multicolumn{2}{|c|}{ Lymphocytes } & $0.50(0.3-0.9)$ \\
\hline \multicolumn{2}{|c|}{ Neutrophils } & $2.0(1.7-2.4)$ \\
\hline \multicolumn{2}{|c|}{ Eosinophils } & $0.4(0.1-0.7)$ \\
\hline \multicolumn{2}{|c|}{ Bronchial epithelial cells } & $0.4(0.2-0.6)$ \\
\hline \multicolumn{3}{|c|}{ Bronchial biopsies cells per $0.1 \mathrm{~mm}^{2 \pi}$} \\
\hline \multicolumn{2}{|c|}{ Macrophages } & $1.0(0.8-1.1)$ \\
\hline \multicolumn{2}{|c|}{ Neutrophils } & $0.6(0.3-0.9)$ \\
\hline \multicolumn{2}{|l|}{ Eosinophils } & $0.4(0.2-0.7)$ \\
\hline \multicolumn{2}{|l|}{ CD4+ cells } & $1.7(1.4-1.9)$ \\
\hline CD8+ cells & & $1.3(1.1-1.6)$ \\
\hline Mast cells & & $1.4(1.3-1.5)$ \\
\hline
\end{tabular}

Data are expressed as median (interquartile range), unless otherwise stated. PC20: provocative concentration causing a $20 \%$ fall in FEV1; FEV1: forced expiratory volume in $1 \mathrm{~s}$; \% pred: \% predicted; FVC: forced vital capacity; IVC: inspiratory vital capacity; RV: residual volume; TLC: total lung capacity; IC: inspiratory capacity; $T L, C O$ : transfer factor of the lung for carbon monoxide; $V A$ : alveolar volume. ${ }^{*}$ : post-bronchodilator; ": log transformed.

\section{Univariate associations with clinical and inflammatory parameters at baseline}

At baseline, higher methacholine PC20 values, i.e. less severe $\mathrm{BHR}$ was associated with a higher post-bronchodilator FEV1\% pred, FEV1/IVC, forced expiratory flow (FEF) at 50\% of forced vital capacity (FVC) \% pred and $75 \%$ of FVC \% pred, and a lower reversibility and RV/TLC \% pred (fig. 2 and table S1). For example, for every per cent increase in RV/TLC \% pred, the severity of BHR increased with a doubling concentration of 0.04 , and for every $10^{5}$ increase in the number of neutrophils per millilitre, the severity of BHR increased with doubling concentration of 1.87 (table S1).

A lower methacholine PC20, i.e. more severe BHR, was associated with higher numbers of sputum neutrophils, macrophages, lymphocytes and eosinophils. 

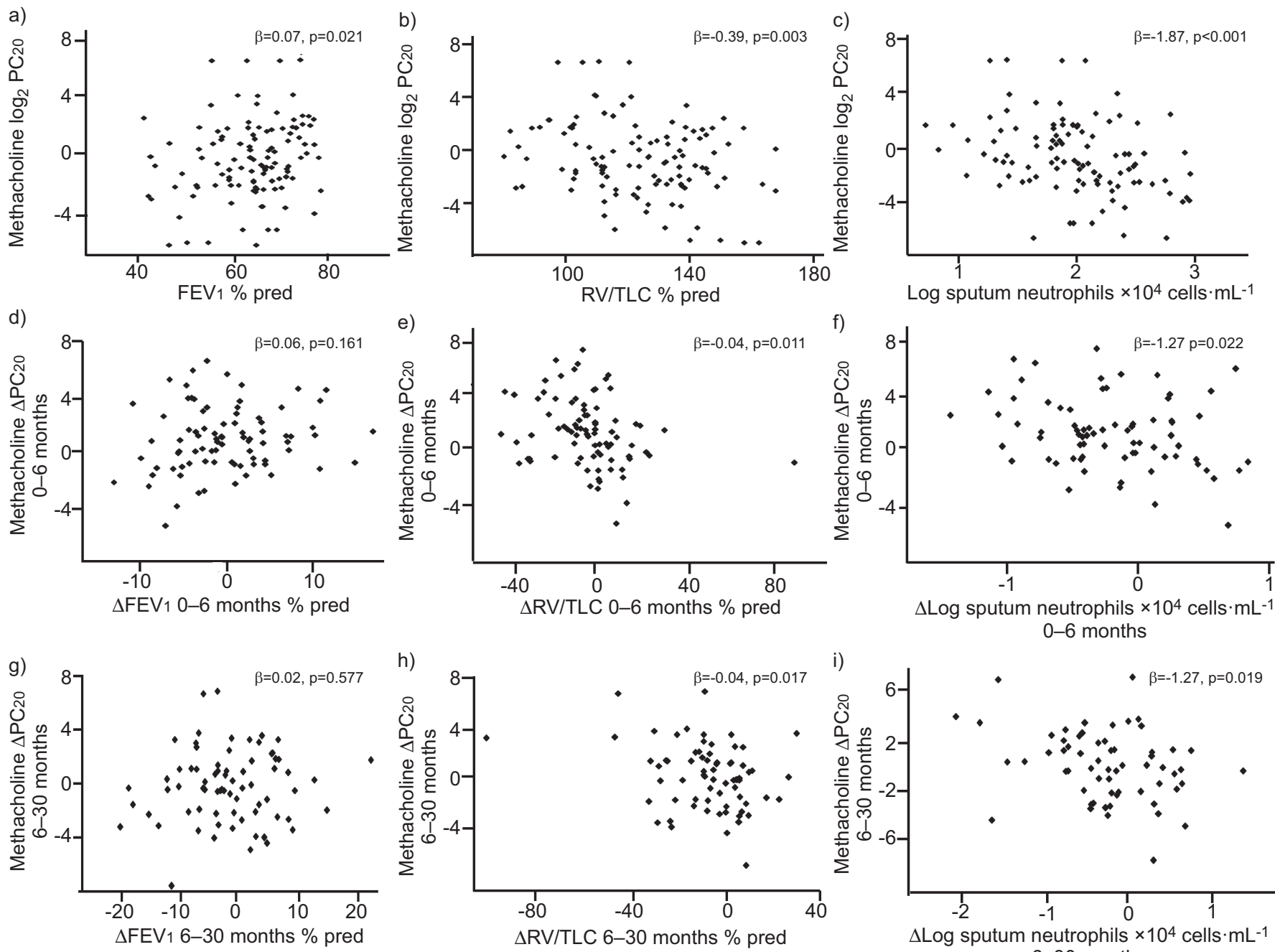

$\Delta$ Log sputum neutrophils $\times 10^{4}$ cells $\cdot \mathrm{mL}^{-1}$ 0-6 months

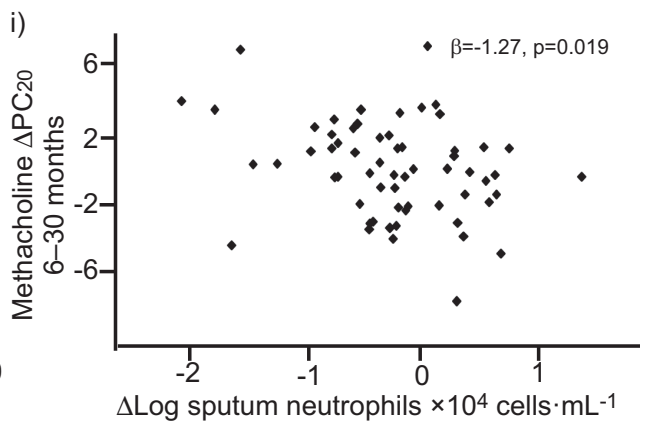

6-30 months

FIGURE 2. Univariate associations between: baseline provocative concentration of methacholine causing a $20 \%$ fall in forced expiratory volume in $1 \mathrm{~s}$ ( $\mathrm{PC} 20$ ), and a) forced expiratory volume in $1 \mathrm{~s}(\mathrm{FEV} 1)$, b) residual volume (RV)/total lung capacity (TLC) and c) the number of sputum neutrophils; change in ( $\Delta$ ) methacholine PC20 between 0 and 6 months of treatment, and d) $\left.\Delta F E V_{1}, e\right) \Delta R V / T L C$ and f) change in the number of sputum neutrophils; and change in methacholine PC20 between 6 and 30 months of treatment, and g) $\Delta \mathrm{FEV}$, h) $\triangle \mathrm{RV} / T L C$ and i) change in the number of sputum neutrophils. \% pred: \% predicted.

\section{Multivariate linear regression with clinical and inflammatory variables}

Females had more severe BHR than males, independent of their baseline level of airway obstruction, age or smoking status. In addition, more severe BHR was independently associated with both a lower FEV1/IVC and a higher number of sputum neutrophils (table 2). When replacing the number of sputum neutrophils with other sputum cell counts that associated with methacholine PC20 with a p-value $<0.1$, a higher number of sputum lymphocytes was the single factor contributing independently to the severity of methacholine PC20 ( $\beta-0.27,95 \% \mathrm{CI}$ -4.55- -0.81).

\section{Analysis on change in methacholine PC20 during the first 6 months}

No significant associations existed between the change in methacholine PC20 during the 6-month treatment and the change in post-bronchodilator FEV1 \% pred or post-bronchodilator
FEV1/IVC (table S2). Improvement in methacholine PC20 was associated with reduction in RV/TLC \% pred and increase in percentage of blood monocytes. Furthermore, improvement in methacholine PC20 was associated with a decrease in the number of sputum neutrophils, but not with other numbers of inflammatory cells in sputum. Finally, improvement in methacholine PC20 was associated with reduction in the number of CD4+ cells in bronchial biopsies.

\section{Multivariate linear regression with changes in clinical and inflammatory variables}

Improvement in methacholine PC20 was significantly and independently associated with a decrease in RV/TLC \% pred and an increase in the percentage of blood monocytes (table 3). In addition, improvement in methacholine PC20 tended to associate with a decrease in the number of neutrophils in sputum $(\mathrm{p}=0.076)$ (table 3$)$. 


\begin{tabular}{lll}
\hline TABLE 2 & $\begin{array}{l}\text { Multivariate regression analysis on the } \\
\text { association between provocative concentration } \\
\text { of methacholine causing a } 20 \% \text { fall in forced }\end{array}$ \\
expiratory volume in $1 \mathrm{~S}(\mathrm{PC} 20)$, and clinical and \\
inflammatory variables in blood, sputum and \\
bronchial biopsies at baseline
\end{tabular}

Data are presented as $\beta(95 \% \mathrm{Cl})$, unless otherwise stated. Bold indicated statistically significant values. FEV1: forced expiratory volume in $1 \mathrm{~s}$; IVC: inspiratory vital capacity; $T \mathrm{~L}, \mathrm{CO}$ : transfer factor of the lung for carbon monoxide; VA: alveolar volume; \% pred: \% predicted. "*: post-bronchodilator; ": $\log$ transformed; ${ }^{+}: \beta-1.67$ (95\% Cl -3.13- -0.22) for sputum lymphocytes $(p=0.025)$.

\begin{tabular}{|c|c|c|c|}
\hline \multirow[t]{2}{*}{ TABLE 3} & \multicolumn{3}{|c|}{$\begin{array}{l}\text { Multivariate regression analysis on the } \\
\text { association between change in ( } \Delta \text { ) provocative } \\
\text { concentration of methacholine causing a } 20 \% \text { fall } \\
\text { in forced expiratory volume in } 1 \mathrm{~s} \text { (PC20) after the } \\
6 \text {-month treatment, and the change in clinical } \\
\text { and inflammatory variables in blood, sputum and } \\
\text { bronchial biopsies }\end{array}$} \\
\hline & & Methacholine $\Delta \log _{2} \mathrm{PC}_{20}$ & p-value \\
\hline \multicolumn{2}{|c|}{ Current smoker } & $-0.66(-1.83-0.52)$ & 0.268 \\
\hline \multicolumn{2}{|c|}{ Age yrs } & $-0.30(-1.04-0.04)$ & 0.423 \\
\hline \multicolumn{2}{|c|}{ Female sex } & $0.26(-1.67-1.72)$ & 0.976 \\
\hline \multicolumn{4}{|c|}{ Treatment group } \\
\hline \multicolumn{2}{|c|}{ Fluticasone/salmeterol } & $0.07(-1.70-1.85)$ & 0.936 \\
\hline \multicolumn{2}{|c|}{ Fluticasone } & $0.36(-1.09-1.81)$ & 0.622 \\
\hline \multicolumn{2}{|c|}{$\Delta R V / T L C \%$ pred } & $-0.03(-0.06-0.00)$ & 0.050 \\
\hline \multicolumn{2}{|c|}{$\Delta$ blood monocytes \% } & $0.35(0.10-0.59)$ & 0.006 \\
\hline \multicolumn{2}{|c|}{$\Delta$ sputum neutrophils $\times 10^{4}$ cells $\cdot \mathrm{mL}^{-1 \#}$} & $-0.98(-2.06-0.11)$ & 0.076 \\
\hline \multicolumn{2}{|c|}{$\Delta$ bronchial CD4+ cells per $0.1 \mathrm{~mm}^{2 *}$} & $-0.93(-2.14-0.27)$ & 0.128 \\
\hline
\end{tabular}

Data are presented as $\beta(95 \% \mathrm{Cl})$, unless otherwise stated. Bold indicates statistically significant values. RV: residual volume; TLC: total lung capacity; \% pred: \% predicted. ${ }^{*}$ : log transformed.

\section{Analysis on changes in methacholine PC20 between 6 and 30 months of treatment with changes in clinical and inflammatory parameters}

A larger improvement in methacholine PC20 associated with a greater reduction in RV/TLC \% pred (fig. 2 and table S2). Furthermore, improvement in methacholine PC20 was associated with decreases in the number of sputum total cells, neutrophils, eosinophils, macrophages and lymphocytes.

\section{Multivariate linear regression with changes in clinical and inflammatory variables}

Multivariate analysis showed that being an ex-smoker, greater reduction in $\mathrm{RV} / \mathrm{TLC} \%$ pred and sputum macrophages independently associated with better improvement in methacholine PC20. These findings were corroborated by the observation that the severity of methacholine PC20 increased when patients were switched from fluticasone to placebo (table 4). When replacing the change in the number of sputum macrophages with changes in other sputum cells that were significantly associated with changes in methacholine PC20 in the univariate analyses, reductions in the number of sputum lymphocytes and neutrophils, but not total sputum cell counts, were independently associated with improvements in BHR ( $\beta-1.56(95 \%$ CI -2.69- -0.42), -1.33 (95\% CI -2.40- -0.27) and -1.11 (95\% CI -2.30$0.08)$, respectively).

\section{DISCUSSION}

Our data show that a more severe BHR in COPD is associated with a higher degree of airway obstruction as reflected by lower FEV1 and FEV1/IVC values. This can be explained by the simple fact that the same bronchoconstrictor response results in a larger drop in FEV1 in a subject with more severe airway obstruction [3, 18-20]. Interestingly, we additionally show that more severe BHR is independently associated with airway inflammation in COPD, as reflected by higher numbers of sputum neutrophils, even after adjusting for age, sex, smoking status and baseline level of airway obstruction. Moreover, we performed a longitudinal analysis, which revealed that both short-term (6 months) and long-term (between 6 and 30 months) treatment-induced improvements in $\mathrm{BHR}$ were independently associated with reductions in numbers of sputum neutrophils, macrophages and lymphocytes.

Many researchers and clinicians consider BHR to be a hallmark of asthma but not of COPD. Our data show that BHR is also present in a considerable proportion of COPD patients. This is in agreement with the findings two earlier studies. First, the Lung Health Study reported a prevalence of BHR of $\sim 60 \%$ in COPD [3]. Secondly, WALKER et al. [21] investigated the effects of methacholine inhalation on respiratory mechanics and found hyperresponsiveness to be present in all 25 included COPD patients. Taking these findings into account, the high prevalence of $94 \%$ for BHR in the GLUCOLD study may not be surprising. Importantly, we specifically excluded patients with asthma by carefully reviewing family charts for earlier diagnosis of asthma, and with an interview and physical examination by a pulmonary physician. In addition, the diagnosis of COPD was verified by including only patients $>45$ yrs with a smoking history $\geqslant 10$ pack-yrs.

In asthma, several studies have shown that the severity of BHR and its treatment-induced improvement is associated with (reduction in) eosinophilic airway inflammation [4, 18, 22]. This contrasts with our findings in COPD. We observed a strong and independent association between BHR and neutrophilic airway inflammation, as reflected by the number of sputum neutrophils both in cross-sectional and longitudinal analyses. This is in agreement with our earlier observations that increased superoxide anion production in peripheral blood neutrophils 


\begin{tabular}{|c|c|c|c|}
\hline \multirow[t]{2}{*}{ TABLE 4} & \multicolumn{3}{|c|}{$\begin{array}{l}\text { Multivariate regression analysis of the } \\
\text { association between change in }(\Delta) \text { provocative } \\
\text { concentration of methacholine causing a } 20 \% \text { fall } \\
\text { in forced expiratory volume in } 1 \mathrm{~s}(\mathrm{PC} 20) \text { between } \\
6 \text { - and } 30 \text {-month treatment, and the changes in } \\
\text { clinical and inflammatory variables in sputum } \\
\text { and bronchial biopsies }\end{array}$} \\
\hline & & $\begin{array}{c}\text { Methacholine } \Delta \log _{2} \\
\text { PC }_{20}\end{array}$ & $\mathrm{p}$-value \\
\hline \multicolumn{2}{|c|}{ Current smoker } & $-1.96(-3.35--0.58)$ & 0.006 \\
\hline \multicolumn{2}{|c|}{ Age yrs } & $-0.05(-0.13-0.04)$ & 0.259 \\
\hline \multicolumn{2}{|l|}{ Female sex } & $0.11(-2.48-2.69)$ & 0.934 \\
\hline \multicolumn{4}{|c|}{ Treatment group } \\
\hline \multicolumn{2}{|c|}{ Fluticasone/salmeterol } & $-0.94(-2.77-0.90)$ & 0.310 \\
\hline \multicolumn{4}{|c|}{ Fluticasone } \\
\hline \multicolumn{2}{|c|}{6 months } & $-2.43(-4.14--0.73)$ & 0.006 \\
\hline \multicolumn{2}{|c|}{30 months } & $-0.12(-1.80-1.56)$ & 0.887 \\
\hline \multicolumn{2}{|c|}{$\Delta \mathrm{RV} / \mathrm{TLC} \%$ pred } & $-0.04(-0.08--0.07)$ & 0.021 \\
\hline \multicolumn{2}{|c|}{$\begin{array}{c}\Delta \text { sputum macrophages } \\
\times 10^{4} \text { cells } \cdot \mathrm{mL}^{-1 *, \pi}\end{array}$} & $-1.72(-2.78--0.68)$ & 0.002 \\
\hline
\end{tabular}

Data are presented as $\beta$ (95\% Cl), unless otherwise stated. Bold indicates statistically significant values. RV: residual volume; TLC: total lung capacity; \% pred: \% predicted. "*: log transformed; $": \beta-1.56(95 \% \mathrm{Cl}-2.69--0.42)$ for sputum lymphocytes $(p=0.008),-1.33(95 \% \mathrm{Cl}-2.40--0.27)$ for sputum neutrophils $(p=0.015)$ and $-1.11(95 \% \mathrm{Cl}-2.30-0.08)$ for total number of cells in sputum $(p=0.066)$

associates with more severe BHR in patients with COPD [23]. There is extensive evidence that neutrophils are important effector cells in COPD. In this context, the findings of BARALDO et al. [24] are of interest. They found that neutrophils infiltrate the airway smooth muscle of patients with COPD to a greater extent than in healthy subjects and this higher degree of neutrophilic infiltration was associated with a lower FEV1. The latter is not surprising, since neutrophils are able to release a variety of pro-inflammatory mediators, including elastase, leukotriene $B_{4}$, myeloperoxidase, defensins, cathepsin $G$ and tumour necrosis factor- $\alpha$. This may lead to damage of the epithelium and lung extracellular matrix, increased mucus secretion, increased permeability of the bronchial mucosa with associated airway wall thickening, and an increased contractile status of airway smooth muscle cells, all contributing to a lower FEV1 and more severe BHR [25].

Furthermore, in our study, improvements in BHR during the last 2 yrs of treatment were independently associated with decreases in the number of sputum macrophages and lymphocytes, indicating that these cells are also important factors contributing to BHR. Taken together, we have now clearly shown that BHR is not merely a surrogate marker for airway obstruction, but also reflects the inflammatory process underlying COPD. Interestingly, improvement in BHR in patients with COPD was not associated with reduction in eosinophilic airway inflammation, as is the case in asthma, again reflecting that the mechanisms underlying BHR are very different between asthma and COPD.
To our surprise, we did not find an independent association between improvement in BHR and reduction in airway obstruction as reflected by FEV1 or FEV1/IVC. Interestingly, reduction in $\mathrm{RV} / \mathrm{TLC} \%$ pred was of importance. This could be due to either a decrease in airway resistance or a reduction in air trapping due to closure of the large and/or small airways. In line with this, HARDAKER et al. [26] showed that an increased RV was a significant independent predictor of BHR in older patients with asthma. In addition, WAGERS et al. [27] showed in a mouse model that airway closure is a central factor contributing to BHR in asthma [28]. The findings of our study suggest that airway closure also contributes BHR in COPD.

We have previously demonstrated that fluticasone and fluticasone/salmeterol significantly improve BHR both after 6-month treatment and 6-30-month treatment [12]. However, in the current multivariate regression analysis, treatment with fluticasone or fluticasone/salmeterol was not independently associated with improvement in BHR, suggesting that treatmentinduced improvement is, at least partly, mediated via reduction in both hyperinflation and airway inflammation.

Similar to findings by KANNER et al. [29], we found that female patients with COPD have more severe BHR than males even after adjustment for baseline airway obstruction. This is especially remarkable given the low number of females in our study. Thus far, the reason why females have more severe BHR is unclear. A possible explanation might be that females have a different type of COPD. It has been shown using computed tomography and histological examination of resected lung specimens that female patients have less emphysema, but thicker bronchiolar airway walls with disproportionately reduced lumens compared to males [30]. Alternatively, hormone-related events may play a role in the development and severity of BHR in COPD [31]. We have extended the findings of KANNER et al. [29] by also investigating the longitudinal changes in BHR after 6- and 30-month treatment. In this way, we were able to show that the level of BHR improved to a similar extent after treatment in males and females with COPD.

The observation that an increase in peripheral blood monocytes after 6-month treatment was independently associated with a decrease in methacholine PC20 was unexpected and intriguing. In this context, our previous findings in asthma are of interest, showing that a higher percentage of peripheral blood monocytes is associated with less severe BHR [4]. Although it has been suggested that peripheral blood monocytes may play a role in the immune responses, relatively little is known about their relation to $\mathrm{BHR}$ in asthma or COPD. Therefore, our finding merits further investigation.

Correlations between treatment-induced changes of methacholine $\mathrm{PC} 20$ and airway inflammation in patients participating in the GLUCOLD study have been presented previously [12]. Changes in mast cells and CD4+ cells associated with change in PC20 in univariate analyses. The previous report only included subgroups of COPD patients using fluticasone or placebo for 30 months, whereas we have now analysed patients from all four treatment groups. In addition, the previous report assessed the change in BHR between 0 and 30 months, while we now analysed the change between 0-6 and 6-30 months. The latter time-points were chosen because a subgroup of 
patients participating in the GLUCOLD study was treated with fluticasone for the first 6 months followed by placebo during the second 24 months. Compatible with our previous report, univariate regression analysis showed that improvement in methacholine PC20 after 6 months was associated with a reduction in the number of $\mathrm{CD}^{+}$cells in bronchial biopsies and tended to associate with reduction in mast cells $(p=0.002$ and $\mathrm{p}=0.06$, respectively; table S2). However, the current multivariate analyses did not show any associations between the number of CD4+ lymphocytes or mast cells and the severity of $\mathrm{BHR}$ at baseline, or between reductions in CD4+ lymphocytes or mast cells and improvements in BHR between 6- and 30month treatment. In addition, the number of CD4+ lymphocytes or mast cells did not contribute independently to improvement of BHR. Thus, in contrast to asthma, our findings do not suggest a large contribution of CD4+ lymphocytes or mast cells to the severity of BHR in COPD, but rather highlight the contribution of sputum neutrophils, lymphocytes and macrophages [32, 33].

In conclusion, the results of our study improve the knowledge on BHR in COPD even though the dispersion of our data is such that it leaves room for additional mechanisms/interactions explaining the mysterious relationship between lung function and biology in COPD. We show that BHR is not only a hallmark of asthma but also occurs in many patients with moderately severe COPD who do not use inhaled corticosteroids. Nevertheless, the factors underlying BHR seem to be different in asthma and COPD. In asthma, the severity of BHR and its treatment-induced improvement have been shown to be associated with (reduction in) the number of eosinophils and mast cells in sputum and bronchial biopsies [4, 18, 22]. This contrasts with our findings in COPD. By performing both crosssectional and longitudinal analyses, we were able to show, for the first time, that BHR in COPD is predominantly associated with airway inflammation reflected by numbers of neutrophils, lymphocytes and macrophages in sputum and bronchial biopsies. In addition, the longitudinal analysis showed that RV/TLC, a measure of air trapping, rather than airflow obstruction contributes to BHR in COPD. Our data indicate that $\mathrm{BHR}$ is an independent trait in COPD and provides additional information on phenotype and disease activity. The role of BHR in COPD deserves further investigation in epidemiological, pathological and pharmacological studies.

\section{SUPPORT STATEMENT}

This study was funded by the Netherlands Organization for Scientific Research (NWO), the Dutch Asthma Foundation, GlaxoSmithKline, the University Medical Center Groningen and Leiden University Medical Center.

\section{STATEMENT OF INTEREST}

Statements of interest for M. van den Berge, T.S. Lapperre, P.J. Sterk, P.S. Hiemstra, N.H.T. ten Hacken, H.A.M. Kerstjens and D.S. Postma, and for the study itself can be found at www.erj.ersjournals.com/site/ misc/statements.xhtml

\section{REFERENCES}

1 Mannino DM, Homa DM, Akinbami LJ, et al. Chronic obstructive pulmonary disease surveillance - United States, 1971-2000. MMWR Surveill Summ 2002; 51: 1-16.
2 Murray CJ, Lopez AD. Mortality by cause for eight regions of the world: Global Burden of Disease Study. Lancet 1997; 349: 1269-1276.

3 Tashkin DP, Altose MD, Bleecker ER, et al. The lung health study: airway responsiveness to inhaled methacholine in smokers with mild to moderate airflow limitation. The Lung Health Study Research Group. Am Rev Respir Dis 1992; 145: 301-310.

4 van den Berge M, Meijer RJ, Kerstjens HAM, et al. PC20 adenosine $5^{\prime}$-monophosphate is more closely associated with airway inflammation in asthma than PC20 methacholine. Am J Respir Crit Care Med 2001; 163: 1546-1550.

5 Wardlaw AJ, Dunnette S, Gleich GJ, et al. Eosinophils and mast cells in bronchoalveolar lavage in subjects with mild asthma. Relationship to bronchial hyperreactivity. Am Rev Respir Dis 1988; 137: 62-69.

6 Ramsdale EH, Hargreave FE. Differences in airway responsiveness in asthma and chronic airflow obstruction. Med Clin North Am 1990; 74: 741-751.

7 Postma DS, Kerstjens HAM. Characteristics of airway hyperresponsiveness in asthma and chronic obstructive pulmonary disease. Am J Respir Crit Care Med 1998; 158: S187-S192.

$8 \mathrm{Xu} \mathrm{X,} \mathrm{Rijcken} \mathrm{B,} \mathrm{Schouten} \mathrm{JP,} \mathrm{et} \mathrm{al.} \mathrm{Airways} \mathrm{responsiveness} \mathrm{and}$ development and remission of chronic respiratory symptoms in adults. Lancet 1997; 350: 1431-1434.

9 Postma DS, de Vries K, Koeter GH, et al. Independent influence of reversibility of air-flow obstruction and nonspecific hyperreactivity on the long-term course of lung function in chronic air-flow obstruction. Am Rev Respir Dis 1986; 134: 276-280.

10 Tashkin DP, Altose MD, Connett JE, et al. Methacholine reactivity predicts changes in lung function over time in smokers with early chronic obstructive pulmonary disease. The Lung Health Study Research Group. Am J Respir Crit Care Med 1996; 153: 1802-1811.

11 Scanlon PD, Connett JE, Waller LA, et al. Smoking cessation and lung function in mild-to-moderate chronic obstructive pulmonary disease. The Lung Health Study. Am J Respir Crit Care Med 2000; 161: 381-390.

12 Lapperre TS, Snoeck-Stroband JB, Gosman MM, et al. Effect of fluticasone with and without salmeterol on pulmonary outcomes in chronic obstructive pulmonary disease: a randomized trial. Ann Intern Med 2009; 151: 517-527.

13 Cockcroft DW. Direct challenge tests: Airway hyperresponsiveness in asthma: its measurement and clinical significance. Chest 2010; 138: 18S-24S.

14 Quanjer PH, Tammeling GJ, Cotes JE, et al. Symbols, abbreviations and units. Working Party Standardization of Lung Function Tests, European Community for Steel and Coal. Eur Respir J 1993; 6: Suppl. 16, 5-40.

15 van den Berge M, Kerstjens HAM, de Reus DM, et al. Provocation with adenosine $5^{\prime}$-monophosphate, but not methacholine, induces sputum eosinophilia. Clin Exp Allergy 2004; 34: 71-76.

16 Fahy JV, Liu J, Wong $\mathrm{H}$, et al. Cellular and biochemical analysis of induced sputum from asthmatic and from healthy subjects. Am Rev Respir Dis 1993; 147: 1126-1131.

17 Lapperre TS, Snoeck-Stroband JB, Gosman MM, et al. Dissociation of lung function and airway inflammation in chronic obstructive pulmonary disease. Am J Respir Crit Care Med 2004; 170: 499-504.

18 van den Berge M, Kerstjens HAM, Meijer RJ, et al. Corticosteroidinduced improvement in the PC20 of adenosine monophosphate is more closely associated with reduction in airway inflammation than improvement in the PC20 of methacholine. Am J Respir Crit Care Med 2001; 164: 1127-1132.

19 Willemse BW, Ten Hacken NH, Rutgers B, et al. Smoking cessation improves both direct and indirect airway hyperresponsiveness in COPD. Eur Respir J 2004; 24: 391-396.

20 Kuwano K, Bosken CH, Pare PD, et al. Small airways dimensions in asthma and in chronic obstructive pulmonary disease. Am Rev Respir Dis 1993; 148: 1220-1225. 
21 Walker PP, Hadcroft J, Costello RW, et al. Lung function changes following methacholine inhalation in COPD. Respir Med 2009; 103 535-541.

22 Sont JK, Willems LN, Bel EH, et al. Clinical control and histopathologic outcome of asthma when using airway hyperresponsiveness as an additional guide to long-term treatment. The AMPUL Study Group. Am J Respir Crit Care Med 1999; 159: 1043-1051.

23 Postma DS, Renkema TE, Noordhoek JA, et al. Association between nonspecific bronchial hyperreactivity and superoxide anion production by polymorphonuclear leukocytes in chronic airflow obstruction. Am Rev Respir Dis 1988; 137: 57-61.

24 Baraldo S, Turato G, Badin C, et al. Neutrophilic infiltration within the airway smooth muscle in patients with COPD. Thorax 2004; 59: 308-312.

25 Schmidt D, Rabe KF. Immune mechanisms of smooth muscle hyperreactivity in asthma. J Allergy Clin Immunol 2000; 105: 673-682.

26 Hardaker KM, Downie SR, Kermode JA, et al. Predictors of airway hyperresponsiveness differ between old and young patients with asthma. Chest 2011; 139: 1395-1401.
27 Wagers S, Lundblad LK, Ekman M, et al. The allergic mouse model of asthma: normal smooth muscle in an abnormal lung? J Appl Physiol 2004; 96: 2019-2027.

28 Irvin CG, Bates JH. Physiologic dysfunction of the asthmatic lung: what's going on down there, anyway? Proc Am Thorac Soc 2009; 6: 306-311.

29 Kanner RE, Connett JE, Altose MD, et al. Gender difference in airway hyperresponsiveness in smokers with mild COPD. The Lung Health Study. Am J Respir Crit Care Med 1994; 150: 956-961.

30 Martinez FJ, Curtis JL, Sciurba F, et al. Sex differences in severe pulmonary emphysema. Am J Respir Crit Care Med 2007; 176: 243-252.

31 Han MK, Postma D, Mannino DM, et al. Gender and chronic obstructive pulmonary disease: why it matters. Am J Respir Crit Care Med 2007; 176: 1179-1184.

32 Ali FR, Kay AB, Larche M. Airway hyperresponsiveness and bronchial mucosal inflammation in T cell peptide-induced asthmatic reactions in atopic subjects. Thorax 2007; 62: 750-757.

33 Gonzalo JA, Qiu Y, Lora JM, et al. Coordinated involvement of mast cells and T cells in allergic mucosal inflammation: critical role of the CC chemokine ligand 1:CCR8 axis. J Immunol 2007; 179: 1740-1750. 